\title{
In Vitro Assessment of Quality Control Parameters of Some Commercially Available Generics of Amlodipine Besylate in Nigerian Drug Market
}

\begin{abstract}
Purpose: To use specific parameters to evaluate the in vitro quality assurance of ten generics of amlodipine besylate $(10 \mathrm{mg})$ tablets commonly sold in the Nigerian drug market.

Methods: Organoleptic and physicochemical properties of 10 brands of the amlodipine besylate tablets were assessed according to official and unofficial standards. Basic quality control parameters evaluated include uniformity of weight, uniformity of content, tablet friability, hardness test, disintegration and dissolution tests.

Results: The results show that all the tablets passed the weight uniformity (mean tablet weights ranging from $155 \pm 003 \mathrm{mg}$ to $404 \pm 0.002 \mathrm{mg}$ ), friability $<5 \%$, disintegration $(<4$ mins $)$ and dissolution tests $(>70 \%$ released within 40 mins). While seven of the ten brands passed the uniformity of content, two out of the three brands that failed the test were unregistered by NAFDAC. The seven brands can be used interchangeably with the branded, Amlovar ${ }^{\circledR}$.

Conclusion: The finding of this research further underscores the need for stakeholders and end users to insist on the use of only duly registered products by the regulatory body.
\end{abstract}

Keywords: Amlodipine besylate, control parameters, generics.
Florence E Eichie

Matthew I Arhewoh

Jude E Isesele

Kikelomo T Olatunji

Department of Pharmaceutics and Pharmaceutical Technology, Faculty of Pharmacy University of Benin, Benin City, Nigeria.

*For correspondence:

Email: eichiefe@yahoo.com

This article is available in Embase, Index Corpenicus, Scopus, PubsHub, Chemical Abstracts, Socolar, EBSCO, African Journal Online, African Index Medicus, Open-J-Gate, Directory of Open Access Journals (DOAJ) databases

\section{Introduction}

Medication cost is a chief determinant of the affordability and compliance to any treatment regimen. Branded drug products from the multinational companies are highly advertised and promoted through electronic media, hand bills, newspapers and printed matters [1]. There is a general belief that the more expensive and

e103 aggressively promoted a particular drug product is, the more effective and widely accepted the product. The long-term effect of these promotional strategies is the high cost of the medication and with a resultant effect of inability of the patient to afford the medication and hence poor compliance to treatment regimen [1]. In order to overcome these problems, efforts have been made to source for the unbranded drug products (i.e. the generics), which are cheaper

Int J Health Res, March 2011; 4(1): 57 
and are expected to be bio-equivalent to the branded. However, this has led to the overwhelming influx of so many generic products particularly from the Asian Pacific into many third World/Developing nations in African continent and particularly Nigeria [2]. Some of these drugs have been reported to be substandard, counterfeit and most often are cheaper in order to attract higher market patronage with the resultant implication (2).

A counterfeit medicine as defined by the World Health Organization (WHO) is one that is deliberately and fraudulently formulated and/or mislabeled with respect to identity and/or source [3]. This is applicable to both branded and generic products and may include products with the correct ingredients or with the wrong ingredients, without active ingredients, insufficient active ingredients, with fake packaging. Previous studies revealed that the causes responsible for the availability of counterfeit drugs in Nigeria include inadequate laws, lack of implementation of existing laws by the drug law enforcement agencies, porosity in the National boarders, inability to afford the actual costs of drugs, poverty, ignorance and corruption [1]. Rapid influx of counterfeit and fake drugs has created some alarming fears and worries on the minds of the patients (the end users) and stakeholders over the years. Quality control parameters are important tools that can be used in assessing the genuine quality of content before their consideration for possible substitution and/or interchangeability of different multi-source brand of a drug [4].

Amlodipine, a structurally related compound to nifedipine is a calcium channel blocker, which in addition to its anti-angina and anti arrhythmic effects also dilates peripheral arterioles and reduces blood pressure [5]. This multifaceted function in mediating cardiac activity has led to its popularity in terms of its wide acceptance and use in hypertension management. Again, amlodipine is well tolerated by majority of patients with very limited side effects. Its prolonged half-life ( $\mathrm{t}^{1 / 2}$ of $35-50$ hours) when administered at a dose of $10 \mathrm{mg}$ daily offers maximum convenience to the patient [5]. In order to enhance patients' affordability of their medications, stakeholders have resorted to source for generics, which supposedly should contain the same amount of the active, as do, the expensive unaffordable brands. Previous workers [6,7] have emphasized the need to evaluate the in vitro pharmaceutical quality assurance of certain drugs e.g., quinine and ibuprofen, respectively. A search in the literature showed that in Nigeria, there has been no such in-vitro assessment of the pharmaceutical quality assurance of amlodipine; an anti-hypertensive drug with so many generics available for substitution for the brand Amlovar ${ }^{\circledR}$ which is very expensive and unaffordable by the patients. Hence, this study undertakes such evaluation.

\section{Experimental}

\section{Materials}

Samples of amlodipine tablets (10mg) of different generics were purchased from Pharmacies across three States in Nigeria (Anambra, Edo and Ondo) respectively. No particular sampling procedure was employed other than one of the researchers posing as a normal customer, purchased at least a minimum of 100 number of tablets of a particular generic without a prescription. The different brands were obtained from drug stores wherever they could be found until ten generic samples were collected. The pure amlodipine powder sample was received from Neimeth Pharmaceuticals Limited, Nigeria as a gift. All other reagents employed in the study were used as received and they were of analytical grade.

\section{Methods}

\section{Physical evaluation of the labels}

As part of the evaluation procedure, the ten generics were coded as "AM" and numbered 1 10 for easy identification. Following the purchase of the samples, labeling informations such as manufacturer's address and country of origin of the brands, batch numbers, manufacturing dates, labeled strength and registration status by the National Agency for Food and Drugs Administration and Control (NAFDAC) were

Int J Health Res, March 2011; 4(1): $\quad 58$ 
Table 1: Label information on amlodipine tablets evaluated

\begin{tabular}{llllllll}
\hline $\begin{array}{l}\text { Brand } \\
\text { code }\end{array}$ & $\begin{array}{l}\text { Brand } \\
\text { name }\end{array}$ & $\begin{array}{l}\text { Batch } \\
\text { number }\end{array}$ & $\begin{array}{l}\text { Manuf } \\
\text { Date }\end{array}$ & $\begin{array}{l}\text { Expiry } \\
\text { Date }\end{array}$ & $\begin{array}{l}\text { Labeled } \\
\text { strength }\end{array}$ & $\begin{array}{l}\text { NADAC } \\
\text { N0 }\end{array}$ & $\begin{array}{l}\text { Country } \\
\text { of origin }\end{array}$ \\
\hline AM 1 & Amlovar & 90105004 & Sep-09 & Sep-12 & $10 \mathrm{mg}$ & A4-0333 & Nigeria \\
AM2 & Amlovasc & C92565 & Apr-08 & Apr-11 & $10 \mathrm{mg}$ & NIL & Uk \\
AM 3 & Swivasc & BV0901 & Jan-09 & Dec-10 & $10 \mathrm{mg}$ & Aa2279 & India \\
AM4 & Lofra & EA0059A & Nil & Jan-11 & $10 \mathrm{mg}$ & A40787 & Portugal \\
AM5 & Novasc & 910276631 & NIL & Jun-13 & $10 \mathrm{mg}$ & 04-5354 & Germany \\
AM6 & Cardipret & ZN107901 & Jul-09 & Jun-12 & $10 \mathrm{mg}$ & A4-2639 & India \\
AM7 & Amlovasc & 804211500 & Apr-09 & Apr-11 & $10 \mathrm{mg}$ & A4-1338 & Turkey \\
AM8 & Amlodipine & OB15UH & Nil & Feb-15 & $10 \mathrm{mg}$ & Nil & Uk \\
AM9 & Asomex & 01B09025 & Nov-09 & Oct.-11 & $10 \mathrm{mg}$ & 04-9891 & India \\
AM!0 & Amlosam & 905 & May-09 & Apr-11 & $10 \mathrm{mg}$ & A4-2447 & India \\
\hline
\end{tabular}

Table 2: Organoleptic properties of the various generics of amlodipine investigated

\begin{tabular}{llllllll}
\hline $\begin{array}{l}\text { Brand } \\
\text { code }\end{array}$ & Colour & Shape & $\begin{array}{l}\text { Inscription } \\
\text { top/bottom }\end{array}$ & $\begin{array}{l}\text { Mean } \\
\text { disintegration } \\
\text { time }(\mathrm{sec})\end{array}$ & $\begin{array}{l}\text { Friability } \\
(\%)\end{array}$ & $\begin{array}{l}\text { Mean weight } \\
(\mathrm{g}) \pm \text { SD }\end{array}$ & $\begin{array}{l}\text { Percentage } \\
\text { content }(\%)\end{array}$ \\
\hline AM1 & White & Hexagon & PGU/10 \& N & 13 & 0.1 & $0.389 \pm 0.007$ & 101.6 \\
AM2 & White & Oval & R \& 178 & 17 & 0.2 & $0.314 \pm 0.004$ & 80 \\
AM3 & Off white & Round & A \& 10 & 136 & 0.3 & $0.129 \pm 0.004$ & 97 \\
AM4 & White & Round & MP \& A/10 & 6 & 0.2 & $0.396 \pm 0.006$ & 104.2 \\
AM5 & White & Octagon & Amlo-10 \& Pfizer & 8 & 0 & $0.404 \pm 0.002$ & 100.2 \\
AM6 & Off white & Oval & Cadiprot 10 & 76 & 3.5 & $0.155 \pm 0.003$ & 96.5 \\
AM7 & White & Round & - & 7 & 7.5 & $0.398 \pm 0.008$ & 95.5 \\
AM8 & White & Round & AB10 & 11 & 21.1 & $0.397 \pm 0.004$ & 78.9 \\
AM9 & Yellow & Heart & A \& 5 & 186 & 21.4 & $0.103 \pm 0.003$ & 78.6 \\
AM10 & White & Oval & - & 3.2 & $0.155 \pm 0.004$ & 96.8 \\
\hline
\end{tabular}

recorded from the product labels where available (Table 1).

\section{Evaluation of the organoleptic properties of the tablets}

Preliminary evaluation of the organoleptic properties of the tablets was carried out for all samples following purchases. The following parameters were evaluated: colour, shape of the tablet, taste, inscription, odour and coating types were analysed objectively by three different assessors and the decision of at least two assessors were considered valid and tabulated as shown in Table 2.

\section{Analysis of physicochemical properties of tablets}

The tablets were further assessed for uniformity of weight, disintegration time, content uniformity

e105 and dissolution rate according to B.P. 2003 [8]. Weight uniformity was carried out by determining the weight of twenty randomly selected tablets from each brand using a digital weighing balance (College B154, Mettler Toledo, Switzerland) while the disintegration time of six tablets per brand was determined in distilled water maintained at $37 \pm 0.5^{\circ} \mathrm{C}$ using Manesty Tablet Disintegration Apparatus (Manesty Machines, Liverpool, England). The dissolution profiles were carried out using dissolution test apparatus (Model: Caleva). This was fitted with a basket rotated at $100 \mathrm{rpm}$ using $800 \mathrm{ml}$ of $0.1 \mathrm{M}$ hydrochloric acid solution as dissolution medium maintained at $37 \pm 0.5^{\circ} \mathrm{C}$. One tablet at a time from each brand was placed in the basket and lowered into the vessel containing the dissolution medium. A $5 \mathrm{ml}$ sample was withdrawn at various intervals and replaced with an equivalent volume maintained at same temperature $37 \pm 0.5^{\circ} \mathrm{C}$ of the dissolution medium. The sample was filtered and

Int J Health Res, March 2011; 4(1): 59 
diluted with an equal volume of $0.1 \mathrm{M} \mathrm{HCl}$. This was continued for 60 mins. The absorbance of the resulting solutions was measured at $\lambda_{\text {max. }} 238 \mathrm{~nm}$, using UV/Visible spectrophotometer (PG instruments Ltd, model T70). The test was carried out in triplicates and mean values are reported.

\section{Results and Discussion}

The result of organoleptic properties of tablets is presented in Table 2. The tablets varied in shapes and surface inscriptions. The inscriptions appeared smooth and unbroken on the tablet surface (Table 2). They were all evenly coloured and whitish. They were all however, uncoated, odourless and tasteless. Tablet shapes and colours are used primarily for the physical identification of dosage forms, while inscriptions are written specifically to identify the tablet with its manufacturer. However, most tablets are white hence the need for further tests to validate their, properties. The results of weight uniformity, disintegration time and percentage content are shown in table 2. The BP 2003 test for uniformity of tablet weight indicates that for tablets weighing $250 \mathrm{mg}$ and over, the percentage deviation above average weight should be $\pm 5 \%$. All tablets fell within that limit and as such all the brands passed the uniformity of weight test with minimal deviations from their mean weights. Furthermore, the recommended disintegration time for uncoated tablets is less than 15 minutes while for coated tablets and capsules are 30 minutes and as such all the brands passed the disintegration time. The highest disintegration time obtained was for AM10, which was 3 mins. This suggests that the tablets will disintegrate within the acceptable time of 15 mins. Friability is an unofficial test. It is designed to ascertain the ability of the tablets to withstand mechanical breakage due to vibrations associated with transportation and carriage. The results showed that with the exception of AM8 and AM9, the tablets were not friable as less than $5 \%$ was lost after operating the friabilator at $25 \mathrm{rpm}$ for 4 mins. The disintegration time of AM 4 was as low as 6 secs. The result showed that all the brands conformed to the $\mathrm{BP}$ requirement. The conformity of the brands to the $\mathrm{BP}$ specification

e106 for disintegration may be attributed to the appropriate use of disintegrants and other excipients like binders and lubricants by the manufacturers. The type of disintegrant used and the method of incorporation of the disintegrant could also affect the rapid release of the drug into solution. The implications of the disintegration and friability results are that drug manufacturers put in much effort to ensure that the dosage forms they manufacture meet and even exceed officially recommended standards.

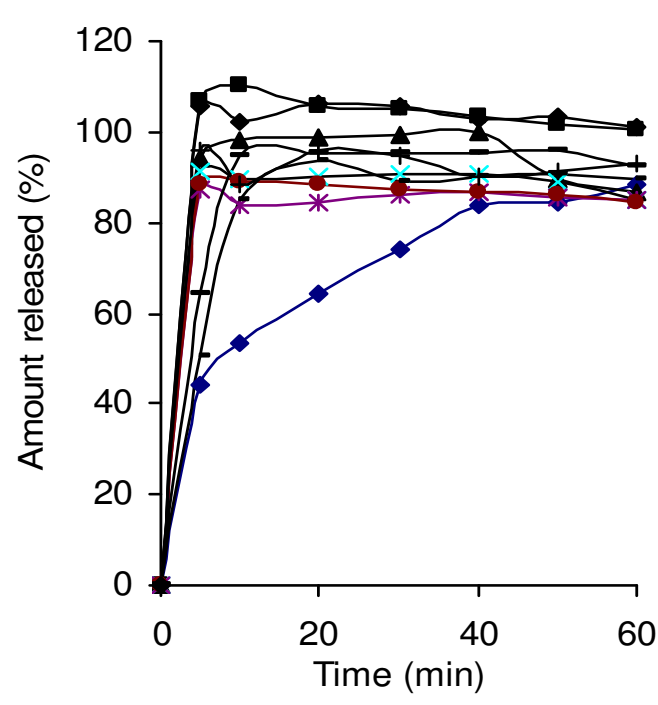

Figure 1: Percentage amount of amlodipine released from the different generic brands

The uniformity of content test is the final test to determine the validity of a well-formulated product. The result of percentage content showed that AM 2, AM 8 and AM 9 had less than $80 \%$ content. Interestingly, AM2 and AM8, were not registered by the regulatory body in Nigeria. This may suggest the probability that the drugs were smuggled into the Country and hence they were regarded as fake and counterfeit drugs and are therefore not considered safe for consumption. Unfortunately, they found their way to the public. Dissolution test provides valuable in vitro data for the development of pharmaceuticals. The BP 2003 [8] states that, $70 \%$ of the uncoated tablet drug should dissolve within 40 mins. All the ten brands released more than $70 \%$ of their contents within 40 mins (figures 1) and hence, sufficient

Int J Health Res, March 2011; 4(1): 60 
amount of the drug should be available for absorption to elicit the expected therapeutic effect when administered.

\section{Conclusion}

All the brands of the amlodipine passed the uniformity of weight test, disintegration test. They were all within the acceptable limits of hardness. All brands displayed excellent dissolution profiles. Seven of the ten brands passed the content uniformity test. It can therefore be concluded that the seven brands are all within acceptable standards and show good quality and very importantly can be interchangeable with the innovator brand (Amlovar®) by Neimeth Pharmaceuticals Nigeria Ltd. The need to emphasize the use of only registered brands is further buttressed.

\section{Acknowledgement}

The Authors wish to acknowledge Neimeth Pharmaceuticals Nigeria Ltd for the free sample of amlodipine powder.

\section{References}

1. Erhun WO, Babalola OO, Erhun MO. Drug regulation and control in Nigeria. The challenges of Counterfeit Drugs. J. Health Popul. Dev. Countries. 2001; 4(2): 23-24.

2. Osibo OO. Faking and Counterfiting of drugs. West Afr J Pharm 1998;12(1): 53-57.

3. World health organization (WHO) Multisource (generic) products: Guidelines on registration requirements to establish interchangeability, The Organization, Geneva, 2004;1-5.

4. Nwodo N, Uzochukwu I., Omeje E. (). Quality control assessment and the possibility of interchangeability between multi-sourced norfloxacin tablets marketed in Nigeria. Scientific Research and Essays 2007;2(8):348352.

5. Katzung BG, Chatterjee K.. Vasodilators and the treatment of angina pectoris. In: Bertrom G. Katzung. Basic and Clinical Pharmacology. $9^{\text {th }}$ ed. Mcraw Hill Companies, New York, 2004;184-199.

6. Nnamdi JA, Arhewoh IM, Okhamafe AO, Enato EFO. Evaluation of the Pharmaceutical Quality of Some Quinine Preparations Sold in Nigeria. Med Princ Pract. 2009;18: 193-197. DOI:10.1159/ 000204349.

7. Eichie FE, Arhewoh IM and Ezeobi OC. () In-vitro evaluation of the pharmaceutical quality of some ibuprofen tablets dispensed in Nigeria. Afr. J. Pharm Pharmacol 2009; 3(10).:491-495.

8. British Pharmacopoeia. The Pharmaceutical Press, Her Majesty's Stationery Office: London 2003;1:124126. 
